Check for updates

Cite this: RSC Adv., 2017, 7, 26028

Received 10th January 2017

Accepted 24th April 2017

DOI: $10.1039 / c 7 r a 00407 a$

rsc.li/rsc-advances

\section{Differential pulse voltammetric determination of an immunosuppressive drug teriflunomide on an edge plane pyrolytic graphite electrode $\uparrow$}

\author{
Kinga Kaczmarska, (D) * Mariola Brycht, Andrzej Leniart and Sławomira Skrzypek
}

In the present work, sensitive and selective determination of teriflunomide (Trf) on an edge plane pyrolytic graphite electrode (EPPGE) using differential pulse voltammetry (DPV) is presented for the first time. It was found that Trf gives a single well-defined oxidation peak at ca. $+1.0 \mathrm{~V} \mathrm{vs}$. Ag/ $\mathrm{AgCl}\left(3 \mathrm{~mol} \mathrm{~L}^{-1} \mathrm{KCl}\right)$ in BrittonRobinson buffer solution (BRBS) at $\mathrm{pH}$ 3.0. The optimization of $\mathrm{pH}$ and DPV parameters was performed. A linear response of Trf was obtained in the range of $2.5 \times 10^{-6}$ to $5.0 \times 10^{-5} \mathrm{~mol} \mathrm{~L}^{-1}$ for EPPGE. The limit of detection (LOD) and limit of quantification (LOQ) were found to be $6.2 \times 10^{-7} \mathrm{~mol} \mathrm{~L}^{-1}$ and $2.1 \times 10^{-6} \mathrm{~mol}$ $\mathrm{L}^{-1}$, respectively. Furthermore, the proposed method was validated and successfully applied for the determination of Trf in the spiked samples of human urine with satisfactory recoveries in the range of 95.2-103.5\% (RSD $=4.2 \%$ ). The influence of potential interfering agents on the peak current response of Trf was also studied. Moreover, to understand the electrooxidation process of Trf on EPPGE, cyclic voltammetry (CV) was employed. Additionally, the surface topography and morphology of the EPPGE were characterized by atomic force microscopy (AFM) and scanning electron microscopy (SEM), respectively. The surface area of EPPGE was calculated based on the Randles-Sevcik equation.

\section{Introduction}

The most famous and incurable autoimmune disease that attacks the central nervous system is multiple sclerosis (MS). ${ }^{1}$ The disease's symptoms occur when the myelin sheaths in nerve cells in the central nervous system (brain and spinal cord) are damaged and consequently cause abnormal impulse transmission. ${ }^{2}$ Multiple sclerosis can cause a variety of symptoms and syndromes, and the most common are movement disorders, sensory, cerebellar (balance disorder), visual disturbances, pain syndromes, and psychiatric symptoms (cognitive and mood disorders). ${ }^{3}$ There is no medicine which could completely stop the progression of the MS, but there are many drugs and therapeutic approaches that are helpful to reduce the symptoms of the disease. ${ }^{3}$ One of them is teriflunomide (Trf, (2Z)-2-cyano-3-hydroxy- $N$-[4-(trifluoromethyl) phenyl]but-2enamide, Fig. 1). Trf is an immunosuppressive drug with antiinflammatory properties which selectively and reversibly inhibits the mitochondrial enzyme dihydroorotate dehydrogenase (DHO-DH) required for the de novo pyrimidine synthesis. ${ }^{4}$ As a consequence of confined de novo pyrimidine production, Trf reduces the proliferation of activated $\mathrm{T}$ and $\mathrm{B}$ cells, which are thought to participate in the inflammatory process in the

University of Lodz, Faculty of Chemistry, Department of Inorganic and Analytical Chemistry, Tamka 12, 91-403 Lodz, Poland. E-mail: kinga.kaczmarska@o2.pl

$\dagger$ Electronic supplementary information (ESI) available. See DOI: 10.1039/c7ra00407a central nervous system. ${ }^{5}$ Trf was accepted by the FDA (Food and Drug Administration, USA) on September 2012, and in the European Union on August 2013 for the treatment of adult patients with relapsing-remitting multiple sclerosis (RRMS) ${ }^{6}$

On the basis of the literature survey, the most popular technique for the determination of Trf in biological fluids or pharmaceutical formulations is chromatography, i.e. highperformance liquid chromatography with UV detection (HPLC-UV), ${ }^{7}$ liquid chromatography-tandem mass spectrometry (LC-MS/MS), ${ }^{8,9}$ liquid chromatography with UV detection (LCUV), ${ }^{9}$ and chromatography-electrospray-tandem mass spectrometry (LC-ESI-MS/MS). ${ }^{10}$ These methods belong to one of the most selective and sensitive, but on the other hand, they have some disadvantages, i.e. time consuming and tedious analysis, expensive instruments and large consumption organic solvents. In addition, the pretreatment procedure (plasma preparation, derivatization, extraction process and purification) is required in the analysis of complex matrices such as human urine, blood or serum. ${ }^{11}$ Electrochemical methods including voltammetric techniques are characterized by high selectivity, sensitivity,<smiles>C/C(O)=C(\C#N)C(=O)Nc1ccc(C(F)(F)F)cc1</smiles>

Fig. 1 The chemical structure of Trf. 
reproducibility, rapid response of detection, and low cost of equipment, and very often they are used for the determination of a wide range of pharmaceutical substances. ${ }^{12-14}$ To the best of our knowledge, no information about the voltammetric determination of Trf has been described in the literature.

So far, the carbon-based electrode materials, i.e. carbon paste ${ }^{15,16}$ glassy carbon, ${ }^{17,18}$ boron-doped diamond, ${ }^{19,20}$ screenprinted carbon, ${ }^{21,22}$ and pyrolytic graphite, ${ }^{23,24}$ were commonly used as working electrodes in electrochemistry, and were shown to be an adequate choice for the large number of applications.

Edge plane pyrolytic graphite (EPPG) is manufactured from highly ordered pyrolytic graphite (HOPG). The EPPGE is produced by cutting the desirable electrode surface geometry such that the layers of graphite lie perpendicular to the surface. ${ }^{25,26}$ Furthermore, the EPPGE is used in voltammetry as working electrode on the grounds of low background current, long term stability and reproducibility, high selectivity and sensitivity. ${ }^{27}$ Moreover, EPPGE is characterized by strong adsorption properties and wide electrochemical window in aqueous solutions. ${ }^{28}$

In this paper, the application of EPPGE as a working electrode and the development of the procedure for the determination of Trf in spiked human urine samples by DPV technique was performed. To date, Trf has not been yet studied electrochemically on the other working electrodes. Attention was paid out to the elucidation of the nature of the used DPV peak of Trf at EPPGE. Special attention was given to the investigation of EPPGE by AFM and SEM and to the evaluation of the electrochemical active surface area.

\section{Materials and methods}

\subsection{Instrumentation}

Electrochemical experiments were performed using a $\mu$ Autolab type II potentiostat-galvanostat (EcoChemie, Autolab B.V., Utrecht, The Netherlands) controlled by GPES software (General Purpose Electrochemical System, version 4.9) in conjunction with an M164 electrode stand (MTM Anko Instruments, Cracow, Poland). A conventional three-electrode glass cell was used with a platinum wire (Pt, 99.99\%, The Mint. of Poland S.A., Warsaw, Poland) as a counter electrode, silver/silver chloride electrode/ potassium chloride (Ag/AgCl, $3.0 \mathrm{~mol} \mathrm{~L}^{-1} \mathrm{KCl}$, Mineral, Poland) as a reference electrode, and an edge plane pyrolytic graphite electrode (EPPGE, ALS Company Ltd, Japan) with an inner disc diameter of $6 \mathrm{~mm}$ as a working electrode. The $\mathrm{pH}$ measurements of the buffer solutions were carried out using an Orion Star $\mathrm{pH}$ meter (Model A111, Thermo Scientific, The Netherlands) with a $\mathrm{pH}$ electrode (type Polilyte Lab, Hamilton, Switzerland). The atomic force microscopy (AFM, Dimension Icon, Bruker, Santa Barbara, CA, USA) was used to characterize the topography of the edge plane pyrolytic graphite electrode surface. The scanning electron microscopy (SEM, Nova NanoSEM450, FEI) was applied to evaluate the surface morphology of EPPGE.

\subsection{Reagents and solutions}

The analytical standard of Trf (CAS Reg. No. 108605-62-5, Selleck Chemicals, Germany) was of $99.71 \%$ purity. Stock solution of $\operatorname{Trf}\left(1.0 \times 10^{-3} \mathrm{~mol} \mathrm{~L}^{-1}\right)$ was prepared in a glass flask by dissolving the substance in a methanol (99.8\%, POCh SA, Gliwice, Poland) and refrigerated when not used. Sulfuric acid (96.0\%, POCh SA, Gliwice, Poland), potassium chloride and potassium ferricyanide (Witko, Poland) were of analytical reagent grade. Britton-Robinson buffer solutions (BRBS) were prepared by mixing the same concentrations $\left(0.04 \mathrm{~mol} \mathrm{~L}^{-1}\right)$ of orthophosphoric acid (85.0\%, POCh SA Gliwice, Poland), acetic acid (99.5\%, POCh SA Gliwice, Poland) and boric acid (Witko, Poland) in triply distilled water, and they were adjusting to the desired $\mathrm{pH}$ value with sodium hydroxide $\left(0.2 \mathrm{~mol} \mathrm{~L}^{-1}\right.$, POCh SA Gliwice, Poland).

The analytical standards of interfering agents, i.e. ascorbic acid, uric acid, paracetamol, dopamine, epinephrine, $\mathrm{K}^{+}, \mathrm{Na}^{+}$, $\mathrm{Ca}^{2+}$, and $\mathrm{Mg}^{2+}$, were of analytical reagent grade. The concentration of stock solutions of interfering agents was $1.0 \times$ $10^{-3} \mathrm{~mol} \mathrm{~L}^{-1}$. All experiments were conducted at room temperature.

\subsection{Measurement procedures}

2.3.1. Voltammetric procedures. Prior to start of the voltammetric measurements, in order to clean and activate the EPPGE surface, CV from $-0.35 \mathrm{~V}$ to $+1.35 \mathrm{~V}$ in $0.1 \mathrm{~mol} \mathrm{~L}^{-1} \mathrm{H}_{2} \mathrm{SO}_{4}$ was performed. CV and DPV were applied for electrochemical studies and quantification of Trf, respectively. CV experiments were performed in the potential range from $+0.5 \mathrm{~V}$ to $+1.3 \mathrm{~V}$ at different scan rates $(\nu)$ from $10 \mathrm{mV} \mathrm{s}^{-1}$ to $400 \mathrm{mV} \mathrm{s}^{-1}$. The optimal conditions for DPV measurements were as follow: BRBS, pH 3.0, modulation amplitude $\left(E_{\mathrm{DP}}\right)$ of $60 \mathrm{mV}$, modulation time $\left(t_{\mathrm{DP}}\right)$ of $30 \mathrm{~ms}$, interval time $\left(t_{\mathrm{int}}\right)$ of $200 \mathrm{~ms}$, and step potential $\left(\Delta E_{\mathrm{s}}\right)$ of $10 \mathrm{mV}$. Following procedure was applied to obtain the blank voltammograms: $9 \mathrm{~mL}$ of the supporting electrolyte and $1 \mathrm{~mL}$ of the methanol were transferred into the cell. To achieve the DP voltammograms of Trf, appropriate volumes of the stock solutions of immunosuppressive drug and methanol were added to the cell containing supporting electrolyte $(9 \mathrm{~mL})$ on total bulk of $10 \mathrm{~mL}$. The calibration curve was constructed from the average of four replicate measurements for each concentration. The measured signals were evaluated by using the moving average with a peak width of $2 \mathrm{mV}$ included in GPES 4.9 software. The linear least-square regression was used in the construction of calibration curve. The results were reported with confidence interval for $95 \%$ probability. LOD was calculated as three times the standard deviation of peak heights divided by the slope of the calibration curve while LOQ was counted as the concentration of the analyte, which gave a signal ten times the standard deviation of the lowest evaluable concentration. $^{29}$

2.3.2. Procedure for human urine samples spiked with Trf. Three samples of human urine were collected from healthy volunteers on the same day of the experiments, and stored in refrigerator at $4{ }^{\circ} \mathrm{C}$ when not used. All experiments were maintained in accordance with the guidelines Rector's order of the University of Lodz and approved by the Commission for Bioethics of Research of University of Lodz. Informed consent was obtained from human subjects. Fresh samples of urine 
were prepared only by dilution (without purification and filtration). The procedure of diluting human urine samples was performed as follows: $10 \mu \mathrm{L}$ of urine was transferred to a $10 \mathrm{~mL}$ calibrated flask and filled up to the mark with water. Thereafter, in order to investigate the possible interferences from urine, 1 $\mathrm{mL}$ of diluted urine was placed in a voltammetric cell containing $9 \mathrm{~mL}$ supporting electrolyte. Then, the DP voltammogram of the blank was recorded. In the next step, the spiked samples of urine were prepared as follows: $10 \mu \mathrm{L}$ of urine and $1 \mathrm{~mL}$ of $\mathrm{Trf}$ $\left(1.0 \times 10^{-3} \mathrm{~mol} \mathrm{~L}^{-1}\right)$ were added to a $10 \mathrm{~mL}$ calibrated flask and was diluted to the mark with water (the final Trf concentration in cell was $1.0 \times 10^{-5} \mathrm{~mol} \mathrm{~L}^{-1}$ ). Next, $1 \mathrm{~mL}$ of spiked diluted urine with Trf was transferred to the electrochemical cell containing $9 \mathrm{~mL}$ B-R buffer, $\mathrm{pH}$ 3.0. The DPV curve was recorded under the same conditions as for diluted urine. The concentration of Trf was measured by DPV using the standard addition method. Therefore, succeeding additions of Trf were added to electrochemical cell at corresponding concentrations of: $5.0 \times$ $10^{-6}, 1.0 \times 10^{-5}$, and $1.5 \times 10^{-5} \mathrm{~mol} \mathrm{~L}^{-1}$. The standard addition curve was performed in triplicate $(n=3)$ with confidence interval for probability $(p)$ of $95 \%$.

2.3.3. Interference study procedure. The influence of potential interfering agents (Int) such as metals of cations and organic substances was investigated as follows: appropriate volume of the stock solutions of Trf and methanol were transferred to the voltammetric cell containing $9 \mathrm{~mL}$ of supporting electrolyte (the total concentration of Trf in the cell was $1.0 \times$ $10^{-5} \mathrm{~mol} \mathrm{~L}^{-1}$ ). Then, the DP voltammogram of Trf was recorded. Thereafter, the appropriate volumes of the Int were added to the cell containing Trf and supporting electrolyte at concentrations of $5.0 \times 10^{-6}, 1.0 \times 10^{-5}, 2.0 \times 10^{-5}, 5.0 \times$ $10^{-5}$, and $1.0 \times 10^{-4} \mathrm{~mol} \mathrm{~L}^{-1}$. The voltammograms were recorded for each addition of Int. The ratios of varying concentrations of Int to constant concentration of $\operatorname{Trf}(1.0 \times$ $\left.10^{-5} \mathrm{~mol} \mathrm{~L}^{-1}\right)\left(c_{\text {Int }}: c_{\text {Trf }}\right)$ were as follows: $0.5: 1,1: 1,2: 1,5: 1$, and $10: 1$. The evaluation of interferences was accomplished under optimized experimental conditions.

2.3.4. Surface topography and morphology characterization of EPPGE. The atomic force microscopy was used to characterize the surface morphology of the edge plane pyrolytic graphite electrode. Commercially available silicon cantilevers with nominal spring constant of $42 \mathrm{~N} \mathrm{~m}^{-1}$ and resonance frequency of $320 \mathrm{kHz}$ were employed. AFM was operated in tapping mode to obtain the topography images at room temperature.

The scanning electron microscopy was applied to evaluate the surface morphology of EPPGE. In the SEM measurements, a through lens detector (TLD) was used at a beam energy of $5 \mathrm{kV}$.

\section{Results and discussion}

\subsection{Determination of the electrochemical active surface area of EPPGE}

In this work, $\mathrm{Fe}(\mathrm{CN})_{6}{ }^{3-/ 4-}$ as common benchmark redox system was selected to determine the electrochemical active surface area of EPPGE by CV and Randles-Sevcik equation. Thus, the cyclic voltammograms of $1.0 \times 10^{-3} \mathrm{~mol} \mathrm{~L}^{-1} \mathrm{~K}_{3}\left[\mathrm{Fe}(\mathrm{CN})_{6}\right]$ in
$0.1 \mathrm{~mol} \mathrm{~L}^{-1} \mathrm{KCl}$ as the supporting electrolyte were recorded at various scan rates $(\nu)$ in the range of $10 \mathrm{mV} \mathrm{s}^{-1}$ to $500 \mathrm{mV} \mathrm{s}^{-1}$. A well-defined redox couple was observed due to the presence of ferricyanide/ferrocyanide. As can be seen from the voltammograms recorded for the different scan rates (Fig. A1 in ESI $\dagger$ ), two well-defined signals (anodic and cathodic peaks) were obtained. It was found that the peak-to-peak separation $(\Delta E)$ of cathodic and anodic peak was in the range from $146 \mathrm{mV}$ to $298 \mathrm{mV}$, and the ratio of cathodic $\left(I_{\mathrm{p}, \mathrm{c}}\right)$ and anodic $\left(I_{\mathrm{p}, \mathrm{a}}\right)$ peak current was in the range from 0.96 to 0.99 . The relationship of anodic or cathodic peak current $v s$. the square root of the scan rate $\left(\nu^{1 / 2}\right)$ can be expressed by the equations (eqn (1) and (2)):

$$
\begin{aligned}
I_{\mathrm{p}, \mathrm{a}}(\mathrm{A}) & =3.00 \times 10^{-5} \times \nu^{1 / 2}\left(\mathrm{~V} \mathrm{~s}^{-1}\right)^{1 / 2}+1.31 \times 10^{-6}, \\
\left(R^{2}\right. & =0.9963) \\
I_{\mathrm{p}, \mathrm{c}}(\mathrm{A}) & =-2.42 \times 10^{-5} \times \nu^{1 / 2}\left(\mathrm{~V} \mathrm{~s}^{-1}\right)^{1 / 2}-1.77 \times 10^{-6}, \\
\left(R^{2}\right. & =0.9962)
\end{aligned}
$$

To determine the electrochemical active surface area for a reversible electrode process, $I_{\mathrm{p}}$ is defined by the RandlesSevcik equation $^{30}$ (eqn (3)):

$$
I_{\mathrm{p}}=0.4463\left(\frac{F^{3}}{R T}\right)^{1 / 2} A n^{3 / 2} D^{1 / 2} C_{\mathrm{o}} \nu^{1 / 2}
$$

where $F$ is Faraday constant [ $96485 \mathrm{C} \mathrm{mol}^{-1}$ ], $R$ is the universal gas constant $\left[8.314 \mathrm{~J} \mathrm{~mol}^{-1} \mathrm{~K}^{-1}\right], A$ is the surface area of electrode $\left[\mathrm{cm}^{2}\right], I_{\mathrm{p}}$ refers to the peak current $[\mathrm{A}], n$ is the number of electrons involved in the redox reaction $\left(n=1\right.$ for $\left.\mathrm{K}_{3}\left[\mathrm{Fe}(\mathrm{CN})_{6}\right]\right)$, $T$ is the absolute temperature [298 K], $D$ is diffusion coefficient of $\mathrm{K}_{3}\left[\mathrm{Fe}(\mathrm{CN})_{6}\right]\left[7.2 \times 10^{-6} \mathrm{~cm}^{2} \mathrm{~s}^{-1}\right], \nu$ is scan rate $\left[\mathrm{V} \mathrm{s}^{-1}\right]$, and $C_{\mathrm{o}}$ is the concentration of $\mathrm{K}_{3}\left[\mathrm{Fe}(\mathrm{CN})_{6}\right]\left[1 \times 10^{-3} \mathrm{~mol} \mathrm{~L}^{-1}\right]$. Thus, the value of $A$ can easily be calculated from the slope of $I_{\mathrm{p}}$ on $\nu^{1 / 2}$ plot, and the electrochemical active surface area was evaluated as $0.0416 \mathrm{~cm}^{2}$. The obtained $A$ value was closed to the active surface area for another EPPGE. ${ }^{31}$

\subsection{AFM and SEM characterization of EPPGE surface}

Prior to the use of the electrode material for electrochemical analysis, it is important to investigate the working electrode surface. Therefore, the microscopical characteristics of the EPPGE were performed using SEM and AFM. As can be seen from SEM images (Fig. 2B), the surface of EPPGE is fabricated from graphite platelets, which are perpendicular to the basal plane. The edge planes of the graphite platelets are characterized by the different length, height and various spacing. These properties were confirmed by AFM images (height and amplitude images) which are presented in Fig. 2A. The compact areas as well as areas with large crevices can be observed on EPPGE surface, what is clearly visible on the AFM amplitude images. The cross-section profile taken from the AFM height images (Fig. 2A) showed that the depth and width of crevices are from a few nanometers to few hundred nanometers. The roughness surface parameters (RMS) and surface area difference (SAD) were determined using the Bruker Nanoscope Analysis software (version 1.4). It was found that the RMS value for a scan area of 
A

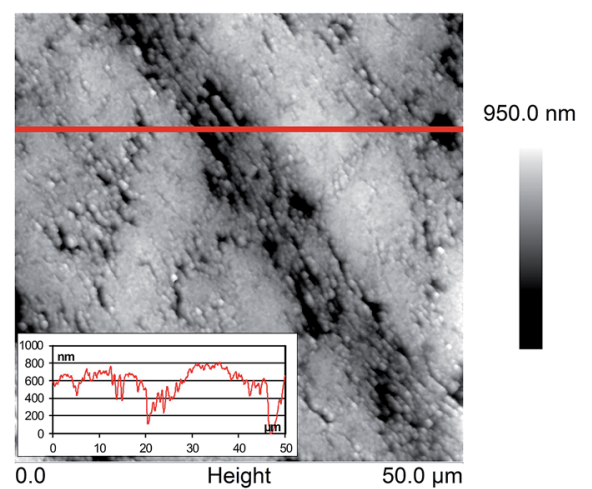

B

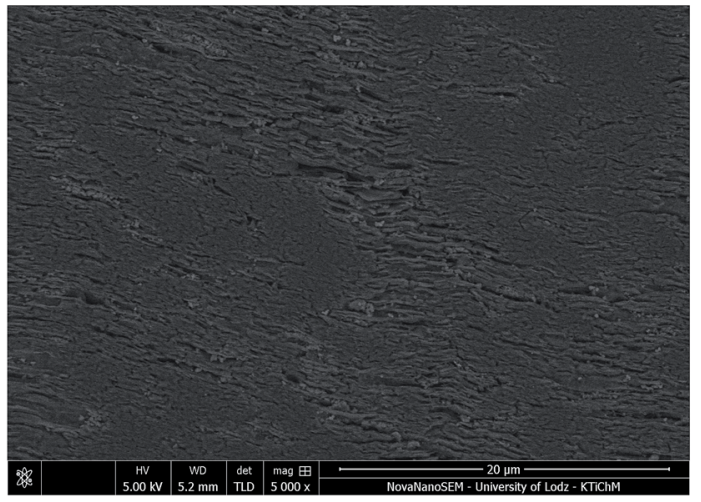

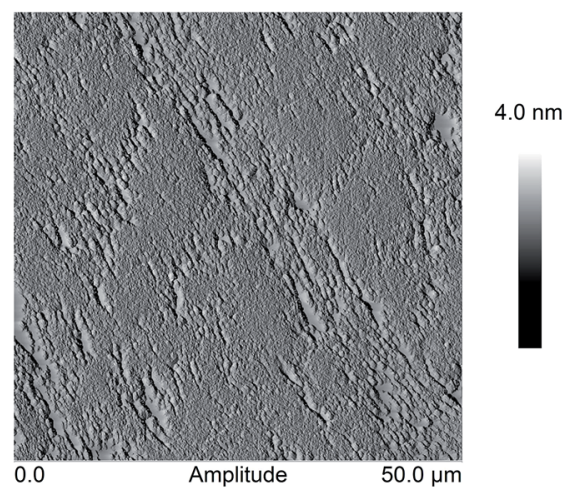

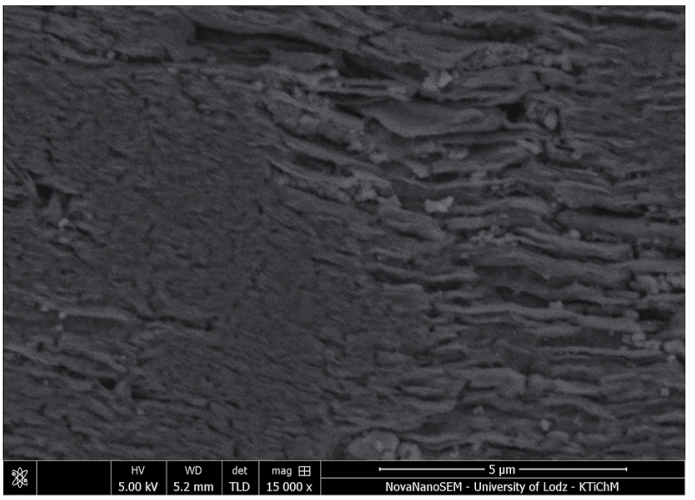

Fig. 2 (A) AFM images (height and amplitude) of EPPGE with the cross-section profile along with the reference lines on height images, (B) SEM images of EPPGE.

$50 \mu \mathrm{m} \times 50 \mu \mathrm{m}$ was equal to $108.3 \pm 22.8 \mathrm{~nm}$, and $\mathrm{SAD}$ value was calculated as $6.1 \pm 0.4 \%$.

\subsection{Electrochemical behavior of Trf}

To evaluate the response of Trf on the EPPGE, the electrochemical study was performed employing CV. The valuable information concerning the electrode reaction mechanism (rate-determining step) can be accomplish from the relationship between the $I_{\mathrm{p}}$ and $\nu$. Thus, the cyclic voltammograms for $\operatorname{Trf}\left(5.0 \times 10^{-5} \mathrm{~mol} \mathrm{~L}^{-1}\right)$ were recorded in BRBS at pH 3.0 at different scan rates from $10 \mathrm{mV} \mathrm{s}^{-1}$ to $400 \mathrm{mV} \mathrm{s}^{-1}$. The welldefined anodic peak of Trf at a potential of $c a$. $+1.0 \mathrm{~V}$ on the EPPGE was obtained as depicted in Fig. 3. Moreover, sufficiently low background current on EPPGE was observed due to low interfacial capacitance (the inset of Fig. 3). It was found that in the presence of Trf, no redox peaks were observed in the cathodic run in the investigated potential window. This behavior suggests an irreversible process on the EPPGE. The peak potential $\left(E_{\mathrm{p}}\right)$ of the oxidation peak of Trf was also dependent on scan rate, and shifted to more positive values with increasing the $\nu$ (Fig. A2A in ESI $\dagger$ ). This behaviour corroborates the irreversibility of the electrode reaction.

Furthermore, the studies on the scan rate were carried out to evaluate the rate-limiting step on EPPGE (diffusion- or adsorption-controlled). The dependences of the $I_{\mathrm{p}} v s . \nu^{1 / 2}$ was linear (Fig. A2B in ESI $\dagger$ ) which is characteristic for a typical diffusion-controlled process. ${ }^{32}$ The above-mentioned relation can be expressed by following equation (eqn (4)):

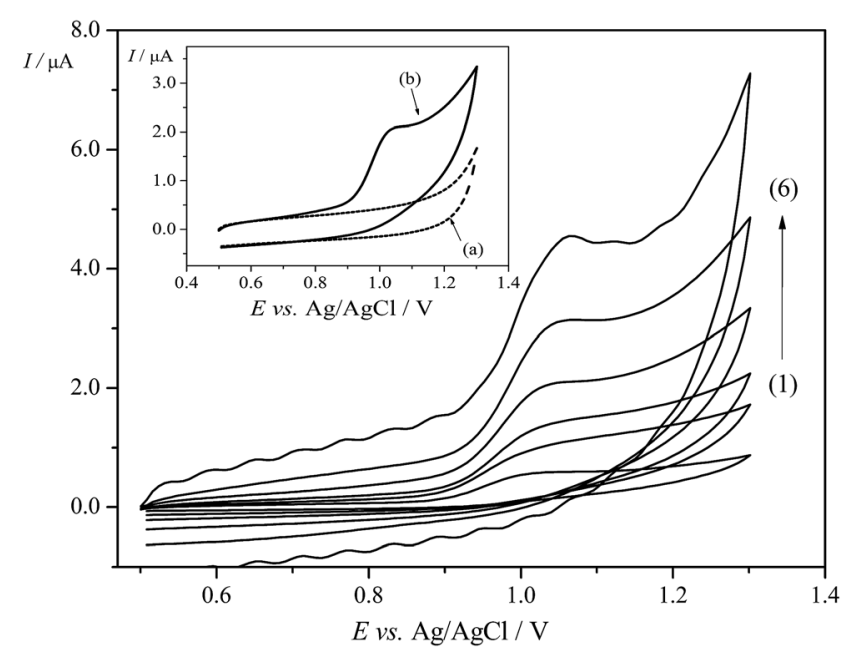

Fig. $3 \mathrm{CVs}$ of $\operatorname{Trf}\left(1.0 \times 10^{-4} \mathrm{~mol} \mathrm{~L}^{-1}\right)$ recorded in BRBS $(\mathrm{pH} 3.0)$ on EPPGE. Scan rates $(\nu)$ : (1) $10,(2) 25$, (3) 50 , (4) 100, (5) 200, and (6) $350 \mathrm{mV} \mathrm{s}^{-1}$. Inset: The CVs of (a) blank (BRBS, pH 3.0) and (b) $1.0 \times$ $10^{-4} \mathrm{~mol} \mathrm{~L}^{-1} \mathrm{Trf}$ in BRBS buffer at $\mathrm{pH} 3.0$ on EPPGE with $\nu=100 \mathrm{mV}$ $\mathrm{s}^{-1}$. 


$$
I_{\mathrm{p}}(\mu \mathrm{A})=0.066 \nu^{1 / 2}\left(\mathrm{mV} \mathrm{s}^{-1}\right)^{1 / 2}-0.023,\left(R^{2}=0.9892\right)
$$

In addition, the effect of logarithm of oxidation peak current $\left(\log I_{\mathrm{p}}\right)$ of $\operatorname{Trf}$ on the logarithm of scan rate $(\log \nu)$ was investigated (Fig. A2C in ESI $\dagger$ ). The above data yields the following equation (eqn (5)):

$$
\log I_{\mathrm{p}}(\mu \mathrm{A})=0.49 \log \nu\left(\mathrm{mV} \mathrm{s}^{-1}\right)-1.17,\left(R^{2}=0.9843\right)
$$

A plot of $\log I_{\mathrm{p}} v s . \log \nu$ gave a straight line with slope of 0.49 . This value is very close to the theoretical value of 0.5 , which indicated that the transfer process of Trf to the electrode surface was diffusion-controlled. ${ }^{33}$

For an irreversible process at $25^{\circ} \mathrm{C}$, the number of electrons taking part in the electrode process of analyte can be calculated from the difference between the $E_{\mathrm{p}}$ and half wave potential $\left(E_{\mathrm{p} / 2}\right)$ according to the equation given by Nicholson and Shain ${ }^{34}$ described as (eqn (6)):

$$
\Delta E_{\mathrm{p}}(\mathrm{mV})=E_{\mathrm{p}}-E_{\mathrm{p} / 2}=(47.7 / \alpha n)
$$

where $\Delta E_{\mathrm{p}}$ is the potential difference, $\alpha$ is the so-called charge transfer coefficient, and $n$ is number of electrons. Thus, the obtained value of $\alpha n$ was calculated, and it was equal to 0.91. Due to the fact that $\alpha$ for irreversible processes is 0.5 , the number of electrons transferred in Trf oxidation on EPPGE was calculated as $1.82(\sim 2)$. The possible oxidation of Trf at EPPGE occurs presumably at the nitrogen of the $p$-trifluorotoluidil moiety forming $\mathrm{N}$-acetylated imine derivative by the nucleophilic addition of methoxy group (Trf was dissolved in methanol) at the para position. Similar conclusion was drown for leflunomide, the metabolite of Trf. ${ }^{35}$ During electrooxidation of Trf on EPPGE, $p$-trifluorotoluidil moiety lost two electrons and one proton. It can be stated that after electrooxidation process of Trf, keto and enol tautomeric forms exist in solution. Generally, the equilibrium between tautomers is not only rapid under normal conditions, but it is often stronger in acidic medium, ${ }^{36}$ and keto-enol tautomerism alludes to a chemical equilibrium between a keto and an enol forms (an alcohol).
Based on the above considerations, the oxidation mechanism of Trf on EPPGE in acidic medium was proposed, and it is presented on Scheme $1 .^{36}$

\subsection{Influence of $\mathrm{pH}$ and $\mathrm{DPV}$ parameters on the voltammetric behavior of Trf}

An important stage in this study was choosing the $\mathrm{pH}$ of the supporting electrolyte. In our work, the effect of BRBS on Trf $\left(5.0 \times 10^{-5} \mathrm{~mol} \mathrm{~L}^{-1}\right)$ over a $\mathrm{pH}$ range from 2.0 to 11.0 was examined using DPV. The obtained voltammograms are depicted in Fig. 4A. It was found that Trf provided one oxidation peak at positive potentials (in the range of $c a$. 0.9-1.0 V) in BRBS, except for the $\mathrm{pH} 4.0$ and 5.0 where two peaks were observed at potentials of $c a$. $+0.9 \mathrm{~V}$ and $+1.2 \mathrm{~V}$, respectively. As can be seen from Fig. $4 \mathrm{~B}(\diamond$, left $y$ axis), the rapid enhancement of the peak current of Trf with increasing $\mathrm{pH}$ was indicated with maximum at $\mathrm{pH}$ 4.0. Thereafter, $I_{\mathrm{p}}$ started to decrease progressively. The highest analytical signal was obtained at $\mathrm{pH} 4.0$, nevertheless, the best results for Trf, i.e. well-defined voltammetric profile peak and low background current were obtained with BRBS at $\mathrm{pH}$ 3.0, thus, this medium was used for further voltammetric experiments.

In addition, the shift of the peak potential of Trf was observed with increasing $\mathrm{pH}$ as depicted in Fig. 4B $(\diamond$, right $y$ axis). The evolution of $E_{\mathrm{p}} v s . \mathrm{pH}$ showed two linear segments in the $\mathrm{pH}$ ranges between 2.0 and 4.0 and 4.0 and 11.0. The dependence of anodic peak potential $\left(E_{\mathrm{p}}\right)$ on the $\mathrm{pH}$ of supporting electrolyte can be presented by the following equations (eqn (7) and (8)):

$$
\begin{gathered}
E_{\mathrm{p}}(\mathrm{V})=-0.096 \mathrm{pH}+1.28,\left(R^{2}=0.9991\right) \\
E_{\mathrm{p}}(\mathrm{V})=0.025 \mathrm{pH}+0.801,\left(R^{2}=0.9804\right)
\end{gathered}
$$

It was found that the peak potentials shifted towards less positive values (from +1.09 to $+0.87 \mathrm{~V}$ ) with the slope of $-96 \mathrm{mV}$ $\mathrm{pH}^{-1}$ in the $\mathrm{pH}$ range $2.0-4.0$ (eqn (7)). As can be seen from Fig. $4 \mathrm{~B}$, the peak potentials in the $\mathrm{pH}$ range from 4.0 to 11.0<smiles>C=CC1(OCC)C=CC(=NC(=O)C(C)C(=O)N=C2C=CC(OC)(C(F)(F)F)C=C2)C=C1</smiles>

Scheme 1 Proposed electrooxidation mechanism of Trf on EPPGE. 
were shifted towards more positive values (from +0.87 to +1.07 $\mathrm{V})$ with the slope of $25 \mathrm{mV} \mathrm{pH}^{-1}$. It is worth mentioning that the presence of two linear segments with breakdown in $\mathrm{pH} 4.0$ was observed, and this change can be linked with the $\mathrm{p} K_{\mathrm{a}}$ value of Trf (theoretical value of 3.1). ${ }^{37}$

A very important step in the development of an electroanalytical methodology is optimization of parameters, which can influence the current response. Thus, the DPV parameters such as modulation amplitude $\left(E_{\mathrm{DP}}\right)$, modulation time $\left(t_{\mathrm{DP}}\right)$, and step potential $\left(\Delta E_{\mathrm{s}}\right)$ were studied in order to find the best experimental conditions for the quantification of $\operatorname{Trf}\left(5.0 \times 10^{-5} \mathrm{~mol}\right.$ $\mathrm{L}^{-1}$ ). During optimization, each parameter was gradually changed, while the others were kept a constant value. The DPV parameters, such as step potential of $10 \mathrm{mV}$, modulation amplitude of $60 \mathrm{mV}$, modulation time of $40 \mathrm{~ms}$, and interval time $\left(t_{\text {int }}\right)$ of $200 \mathrm{~ms}$, represent the optimum values with satisfactory height of current response of Trf (Fig. A3 in ESI $\dagger$ ).

\subsection{Analytical characteristics of Trf}

DPV technique was applied for the determination of Trf in BRBS ( $\mathrm{pH}$ 3.0). Calibration curve for quantification of Trf was constructed by plotting the dependence of peak current $v s$. concentration of $\operatorname{Trf}\left(c_{\text {Trf }}\right)$ under previously optimized experimental conditions described in Section 3.4. The proportional increase of the $I_{\mathrm{p}}$ values with increasing $c_{\text {Trf }}$ was observed in the linear dynamic range (LDR) of $2.5 \times 10^{-6}$ to $5.0 \times 10^{-5} \mathrm{~mol} \mathrm{~L}^{-1}$. The linear calibration plot along with error bars is presented in Fig. 5. Equation according to calibration graph is given below (eqn (9)):

$$
I_{\mathrm{p}}(\mu \mathrm{A})=0.031 c_{\operatorname{Trf}}(\mu \mathrm{mol} \mathrm{L}-1)-0.044,\left(R^{2}=0.9995\right)
$$

The characteristics and related validation parameters of the calibration equations are summarized in Table 1. LOD and LOQ were calculated from the data obtained from the analytical

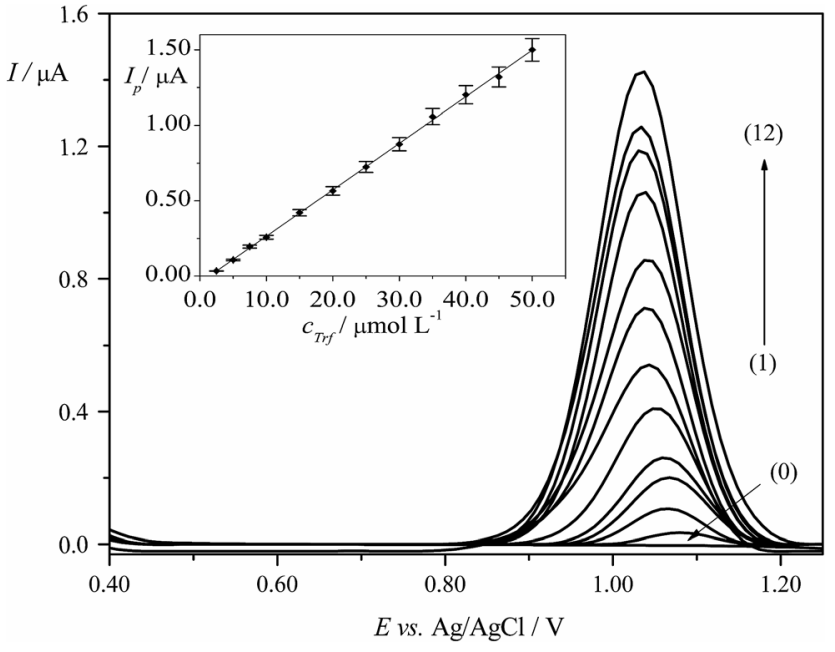

Fig. 5 DPVs of Trf in BRBS ( $\mathrm{pH}$ 3.0). Increasing concentrations of the drug: (0) blank, (1) $2.5 \times 10^{-6}$, (2) $5.0 \times 10^{-6}$, (3) $7.5 \times 10^{-6}$, (4) $1.0 \times$ $10^{-5}$, (5) $1.5 \times 10^{-5}$, (6) $2.0 \times 10^{-5}$, (7) $2.5 \times 10^{-5}$, (8) $3.0 \times 10^{-5}$, (9) 3.5 $\times 10^{-5}$, (10) $4.0 \times 10^{-5}$, (11) $4.5 \times 10^{-5}$, and (12) $5.0 \times 10^{-5} \mathrm{~mol} \mathrm{~L}^{-1}$. The inset presents the averaged currents obtained for four analytical curves. The error bars were constructed as confidence intervals $\left(t_{(p=95 \%, n=4)}=3.18\right)$.

curves as described in the Section 2.3.1, and they were equal to $6.2 \times 10^{-7} \mathrm{~mol} \mathrm{~L}^{-1}$ and $2.1 \times 10^{-6} \mathrm{~mol} \mathrm{~L}^{-1}$, respectively. The precision (repeatability) was evaluated by four repetitive determinations $(n=4)$ for each concentration of Trf. The results showed that relative standard deviation (RSD) of the DPV peak current was ranged from $1.0 \%$ to $5.5 \%$. In addition, the obtained results for different concentrations of Trf in the investigated concentration range were used to calculate the precision (RSD) which was changed in the range from $1.1 \%$ to $8.5 \%$. To conclude, the proposed methodology could be used to determine Trf with satisfactory precision on the EPPGE.

Taking into account the electrochemical behavior of $\operatorname{Trf}$ (paragraph 3.3). it is worth to add, that the obvious shift of the
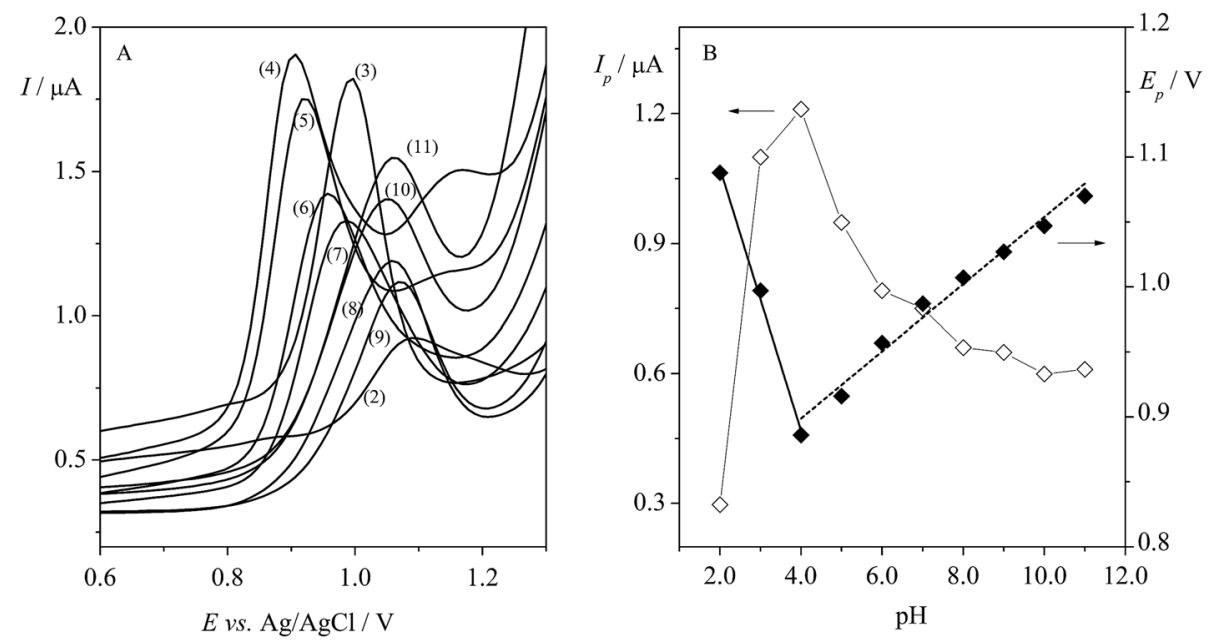

Fig. 4 (A) The effect of $\mathrm{pH}$ on the DPV signal of $5.0 \times 10^{-5} \mathrm{~mol} \mathrm{~L}-1$ Trf recorded in the BRBS in the range of 2.0-11.0. (B) The plot of the DPV peak currents $\left(I_{\mathrm{p}}\right)(\diamond$, left $y$ axis $)$ and peak potentials $\left(E_{\mathrm{p}}\right)(\diamond$, right $y$ axis $) \mathrm{vs}$. $\mathrm{pH}$. Initial measurement parameters: $E_{\mathrm{DP}}=40 \mathrm{mV}, t_{\mathrm{DP}}=60 \mathrm{~ms}, t_{\mathrm{int}}=200$ $\mathrm{ms}, \Delta E_{\mathrm{s}}=10 \mathrm{mV}$. 
Table 1 Analytical parameters obtained from linear regression curve in determination of Trf in BRBS at pH 3.0 using DPV method

\begin{tabular}{|c|c|}
\hline Peak potential $\left(E_{\mathrm{p}}\right) v s . \mathrm{Ag} / \mathrm{AgCl}[\mathrm{V}]$ & $c a .+1.0$ \\
\hline Linear dynamic range (LDR) $\left[\mathrm{mol} \mathrm{L}^{-1}\right]$ & $2.5 \times 10^{-6}$ to $5.0 \times 10^{-}$ \\
\hline Slope $(b)\left[\mu \mathrm{A} \mathrm{L} \mu \mathrm{mol}^{-1}\right]$ & 0.031 \\
\hline $\begin{array}{l}\text { Standard deviation of slope }\left(\mathrm{SD}_{b}\right) \\
{\left[\mu \mathrm{A} \mathrm{L} \mu \mathrm{mol}^{-1}\right]}\end{array}$ & $1.1 \times 10^{-3}$ \\
\hline RSD of slope $\left(\mathrm{RSD}_{b}\right)[\%]$ & 3.6 \\
\hline Intercept $(a)[\mu \mathrm{A}]$ & -0.044 \\
\hline Standard deviation of intercept $\left(\mathrm{SD}_{a}\right)[\mu \mathrm{A}]$ & $1.2 \times 10^{-9}$ \\
\hline RSD of intercept $\left(\operatorname{RSD}_{a}\right)[\%]$ & 3.4 \\
\hline Coefficient of determination $\left(R^{2}\right)$ & 0.9995 \\
\hline Limit of detection (LOD) $\left[\mathrm{mol} \mathrm{L}^{-1}\right]^{a}$ & $6.2 \times 10^{-7}$ \\
\hline Limit of quantification (LOQ) $\left[\mathrm{mol} \mathrm{L}^{-1}\right]^{b}$ & $2.1 \times 10^{-6}$ \\
\hline
\end{tabular}

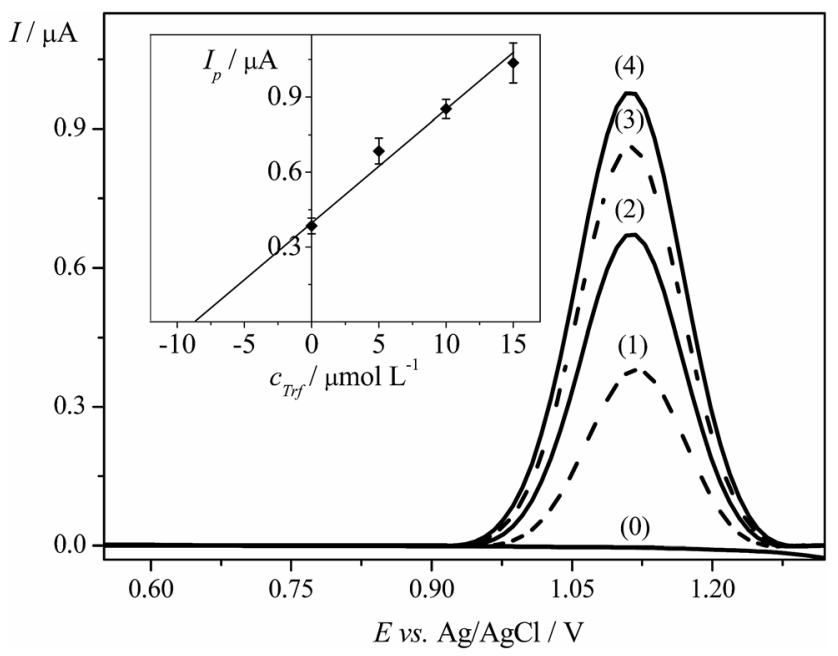

Fig. 6 DPVs obtained for the determination of Trf in the spiked urine samples using the standard addition method; (0) blank, (1) urine sample spiked with $\operatorname{Trf}$, (2) as (1) $+5.0 \times 10^{-6} \mathrm{~mol} \mathrm{~L}^{-1}$; (3) as (1) $+1.0 \times$ $10^{-5} \mathrm{~mol} \mathrm{~L}^{-1}$; (4) as (1) $+1.5 \times 10^{-5} \mathrm{~mol} \mathrm{~L}^{-1}$. The inset presents the corresponding standard addition graph of Trf. The error bars were constructed as confidence intervals $\left(t_{(p=95 \%, n=3)}=4.30\right)$.

peak potential on concentration of Trf (Fig. 5) probably comes from the complexity of the electrode mechanism. The tautomeric equilibrium of Trf is the reactant of the electrode reaction, considering the proton exchange identically as in the product, between $\mathrm{OH}$ group and the $\mathrm{C} 2$ atom where cyano group is attached. Further, protonation of the $\mathrm{N}$ atom occurs in acidic medium, which is the reason for very complex $\mathrm{pH}$ dependence depicted in Fig. 4. Moreover, the other follow-up chemical reactions coupled to the electrode reaction are also probable, which make the electrode reaction irreversible. Thus, a complex combination of tautomeric equilibriums of Trf of the electrode reactions, protonation reaction of the product, and follow-up chemical reactions of the product, all together make a very complex scenario of the electrode mechanism, which is manifested as a dependence of the peak potential on the concentration.

\subsection{Determination of Trf in spiked samples of human urine}

The EPPGE was applied to determine Trf in spiked samples of urine using DPV technique. Before analysis, the fresh urine was collected from volunteer and the samples of urine were prepared in an appropriate way, as described in Section 2.3.2. Furthermore, the standard addition method was applied for the determination of Trf in spiked urine as it was depicted in Section 2.3.2.

The DP voltammograms and the corresponding standard addition plot are illustrated in Fig. 6. The average results of three replicate measurements were presented as confidence interval for $95 \%$ probability. Table 2 displays the results of analysis of human urine samples with sufficient average recovery value of $99.3 \%$ and with the RSD of $4.2 \%$. To conclude, the obtained results showed that the proposed DPV method could be used for the determination of Trf in the complex matrix of human urine samples. The method is adequately accurate and suitable for quantification of Trf.

\subsection{Interference study}

The selectivity of proposed method was estimated via the investigation of the impact of potential interfering agents, which could occur in the human urine as described in Section 2.3.3. It was found that many of interfering substances affected on determination of Trf (except of $\mathrm{Mg}^{2+}$ ). Moreover, no significant decrease on peak current with changing ratio of concentrations of Trf on Int ( $\left.c_{\text {Int }}: c_{\text {Trf }}\right)$ of $0.5: 1,1: 1,2: 1,5: 1$, and $10: 1$ was observed for the uric acid, paracetamol, ascorbic acid, and epinephrine. It was found that initially the peak currents increased for the ratios of ascorbic acid and $\mathrm{K}^{+}, \mathrm{Na}^{+}, \mathrm{Ca}^{2+}$ of $0.5: 1,1: 1$, and then in the ratios of $2: 1,5: 1$, and $10: 1$ slightly decreased. The results are illustrated in Fig. 7. Notwithstanding, it can be stated that an insignificant impact of interferents was observed and the DPV method at EPPGE suggest the promising opportunity for the determination of Trf.

Table 2 Analysis of human urine sample spiked with Trf using DPV $(n=3)$

\begin{tabular}{|c|c|c|c|c|c|}
\hline Sample & Added $\left[\mathrm{mol} \mathrm{L}^{-1}\right]$ & Found $^{a}\left[\mathrm{~mol} \mathrm{~L}^{-1}\right]$ & $\begin{array}{l}\text { Coefficient of } \\
\text { determination }\left(R^{2}\right)\end{array}$ & $\operatorname{RSD}[\%]$ & Recovery $^{b}[\%]$ \\
\hline Urine & $1.00 \times 10^{-5}$ & $(9.93 \pm 1.04) \times 10^{-6}$ & 0.9805 & 4.2 & 99.3 \\
\hline
\end{tabular}




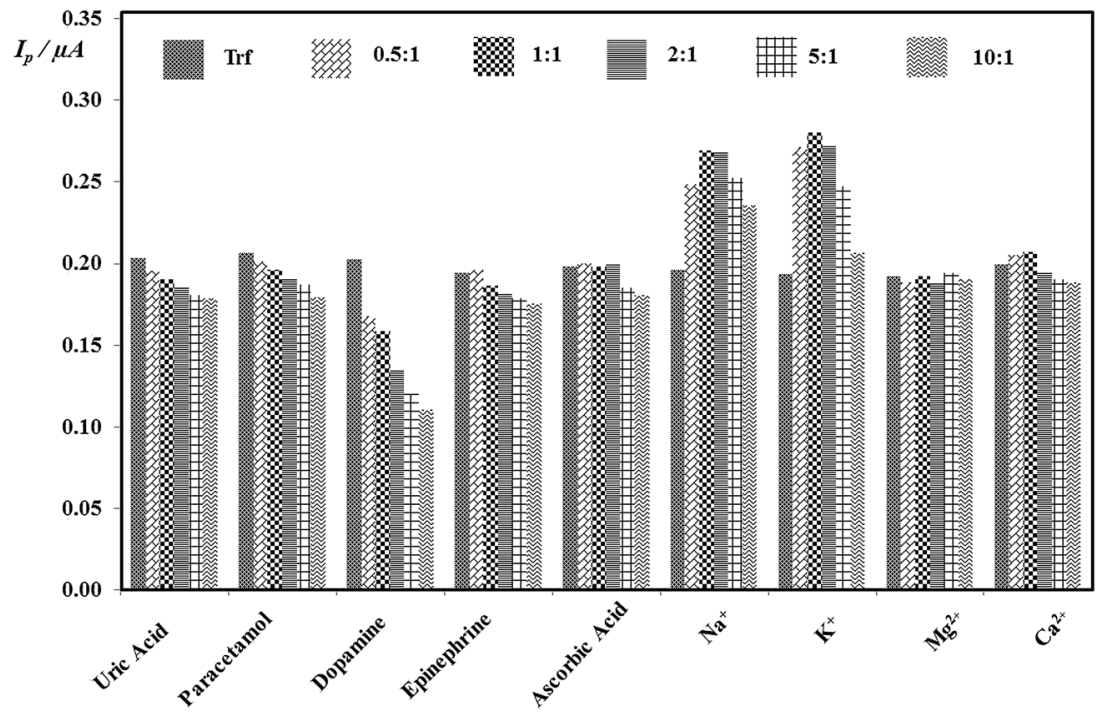

Fig. 7 Histograms of the peak current in the presence the concentration ratios of varying concentrations of each Int to fixed concentration of Trf $\left(c_{\text {Int }}: c_{\text {Trf }}\right)$.

\section{Conclusions}

In the present work, EPPGE in combination with DPV was applied for the first time to develop the novel, simple, fast and inexpensive voltammetric method for quantification of Trf. The proposed procedure was employed for the determination of Trf in the spiked human urine with good recoveries. It was showed that EPPGE electrode may be used as sensitive working electrode in clinical analysis of different biologically active compounds and could substitute complex and costly separation methods. Furthermore, this method requires significantly less organic solvents in comparison with the chromatographic techniques. The interference study revealed that the use of proposed method in this kind of analysis could be limited depending on the presence of some common compounds. Moreover, the proposed electrode can also be used for the analysis of urine samples of patients undergoing treatment with teriflunomide to evaluate Trf present in urine samples with no special pretreatment of samples except suitable dilution. Hence, the EPPGE is also likely to be useful device for quality control analysis in analytical laboratories and pharmaceutical industries.

\section{Acknowledgements}

The authors are very grateful to Prof. Dr Valentin Mirceski (Ss. Cyril and Methodius University, Skopje) for stimulating discussions. This work was supported by Grants No. B1611100001291.02 and B1611100000047.01 from the University of Lodz, Poland.

\section{References}

1 K. Berer and G. Krishnamoorthy, FEBS Lett., 2014, 22, 42074213.
2 F. D. Lublin and S. C. Reingold, Neurology, 1996, 4, 907-911. 3 A. Compston and A. Coles, Lancet, 2002, 9313, 1221-1231.

4 C. Colosimo, A. Gil-Nagel, N. E. Gilhus, A. Rapoport and O. Williams, Handbook of Neurological Therapy, Oxford University Press, New York, 2015.

5 A. Bar-Or, A. Pachner, F. Menguy-Vacheron, J. Kaplan and H. Wiendl, Drugs, 2014, 74, 659-674.

6 European Medicines Agency, Aubagio EU summary of product characteristics, http:/www.ema.europa.eu/docs/ en_GB/document_library/EPAR_Product_Information/ human/002514/WC500148682.pdf, 2015, accessed 20.05.15.

7 E. N. van Roona, J. P. Yska, J. Raemaekers, T. L. Th. A. Jansen, M. van Wanrooy and J. R. B. J. Brouwers, J. Pharm. Biomed. Anal., 2004, 36, 17-22.

8 H. Rakhila, T. Rozek, A. Hopkins, S. Proudman, L. Cleland, M. James and M. Wiesea, J. Pharm. Biomed. Anal., 2011, 55, 325-331.

9 A. Suneetha and R. K. Rajab, Biomed. Chromatogr., 2016, 9, 1371-1377.

10 J. M. Parekh, R. N. Vaghela, D. K. Sutariya, M. Sanyal, M. Yadav and P. S. Shrivastav, J. Chromatogr. B: Anal. Technol. Biomed. Life Sci., 2010, 878, 2217-2225.

11 M. Wang, P. Ma, X. Xi, L. Liu, Y. Wen, K. Liu, L. Sun, Y. Lu and Z. Yin, Talanta, 2016, 161, 278-287.

12 N. A. El-Maali, Bioelectrochemistry, 2004, 64, 99-107.

13 M. Brycht, S. Skrzypek, N. Karadaș, S. Smarzewska, B. BozalPalabiyik, S. A. Özkan and B. Uslu, Ionics, 2015, 21, 23452354.

14 M. Brycht, K. Kaczmarska, B. Uslu, S. A. Ozkan and S. Skrzypek, Diamond Relat. Mater., 2016, 68, 13-22.

15 I. Švancara, K. Vytras, K. Kalcher, A. Walcarius and J. Wang, Electroanalysis, 2009, 21, 7-28.

16 R. Pauliukaite, R. Metelka, I. Švancara, A. Królicka, A. Bobrowski, K. Vytřas, E. Norkus and K. Kalcher, Anal. Bioanal. Chem., 2002, 374, 1155-1158. 
17 A. Leniart, M. Brycht, B. Burnat and S. Skrzypek, Sens. Actuators, B, 2016, 231, 54-63.

18 B. Dogan-Topal, B. Bozal-Palabiyik, S. A. Ozkan and B. Uslu, Rev. Roum. Chim., 2015, 60, 467-475.

19 M. Brycht, S. Skrzypek, K. Kaczmarska, B. Burnat, A. Leniart and N. Gutowska, Electrochim. Acta, 2015, 169, 117-125.

20 M. Brycht, P. Lochyński, J. Barek, S. Skrzypek, K. Kuczewski and K. Schwarzova-Peckova, J. Electroanal. Chem., 2016, 771, 1-9.

21 S. Dal Borgo, H. Sopha, S. Smarzewska, S. B. Hočevar, I. Švancara and R. Metelka, Electroanalysis, 2015, 27, 209216.

22 V. Sosa, C. Barceló, N. Serrano, C. Ariño, J. M. Díaz-Cruz and M. Esteban, Anal. Chim. Acta, 2015, 855, 34-40.

23 R. N. Goyal, A. R. S. Rana and H. Chasta, Bioelectrochemistry, 2012, 83, 46-51.

24 M. Brycht, S. Skrzypek, N. Karadaș, S. Smarzewska, B. BozalPalabiyik, S. A. Özkan and B. Uslu, Ionics, 2015, 21, 23452354.

25 C. E. Banks and R. G. Compton, Anal. Sci., 2005, 21, 12631268.

26 C. E. Banks and R. G. Compton, Analyst, 2006, 131, 15-21.

27 W. J. Lin, C. S. Liao, J. H. Jhang and Y. C. Tsai, Electrochem. Commun., 2009, 11, 2153-2156.
28 S. Kurbanoglu, B. Dogan-Topal, B. Uslu, A. Can and S. A. Ozkan, Electroanalysis, 2013, 25, 1473-1482.

29 A. Krueger, Carbon Materials and Nanotechnology, WileyVCH, Weinheim, 2010.

30 B. Rezaei and S. Damiri, Sens. Actuators, B, 2008, 134, 324331.

31 R. N. Goyal and S. Bishnoi, Bioelectrochemistry, 2010, 79, 234-240.

32 C. M. A. Brett and A. M. O. Brett, Electrochemistry: Principles, Methods and Applications, Oxford University Press, Oxford, UK, 1993.

33 J. Wang, Electroanalytical Techniques in Clinical Chemistry and Laboratory Medicine, Wiley-VCH, New York, 1988.

34 A. Bard and L. R. Faulkner, Electrochemical Methods: Fundamentals and Applications, Wiley, New York, 2nd edn, 2001.

35 R. M. Buoro, T. A. Enache, S. H. P. Serrano and A. M. OliveiraBrett, J. Electroanal. Chem., 2014, 729, 61-67.

$36 \mathrm{H}$. Lund and O. Hammerich, Organic Electrochemistry, Marcel Dekker, 4th edn, 2001.

37 Committee for Medicinal Products for Human Use, Assessment report, European Medicines Agency, http:// www.ema.europa.eu/docs/en_GB/document_library/EPAR_-Public_assessment_report/human/002514/WC500148684. pdf, 2013, accessed 27.06.13. 